\title{
Representation of Young People in British Films Set in Coastal Resorts
}

\author{
Ewa Mazierska
}

https://doi.org/10.30608/HJEAS/2021/27/1/7

\section{ABSTRACT}

This article examines representations of young people in three recent films set in British seaside resorts: Jellyfish (2018), directed by James Gardner Vs. (2018), directed by Ed Lilly, and Eaten by Lions (2018), directed by Jason Wingard, in light of the fact that in the past few decades resorts have been seen as places from which young people try to escape, rather than go to. My essay shows how the experience of those who visit the resorts is different from that of those who live there. It considers the production values, characters, stories, and locations of these films, drawing on secondary research on coastal resorts and their cinematic representations, Erving Goffman's taxonomy of spaces into "front" and "back regions," and Mikhail Bakhtin's concept of the carnivalesque. The article also links the representation of the resort itself to wider discourses about England, class, and race. (EM)

KEYWORDS: disadvantaged youth, front and back regions, the carnivalesque, Mikhail Bakhtin, Blackpool, Margate, promenade

All touristy places, especially coastal resorts, present themselves as places of extraordinary pleasure. They are out to rescue their visitors from their mundane lives by offering them a paradise-like world. This, partly, is facilitated by some natural features of the resorts, most importantly their beaches, as well as the specific architecture they boast, such as piers, promenades, fun-fairs, casinos, and ballrooms, whose function is, primarily, to provide 
pleasure, or even to put their users in an ecstatic state. However, while there are plenty of factors that lure visitors to seaside resorts, mention must be made of those who live there all year round and often earn their living by serving the holidaymakers. In recent years, permanent residents of resort towns have received much attention in Britain, probably more than the attractions themselves, although, of course, these two aspects of economy and culture are closely connected. One can find numerous articles about the social problems haunting British coastal resorts, especially Blackpool, such as the high number of prescriptions issued for anti-depressants per capita, low full-time average wages (O'Connor), these places having some of the most deprived neighborhoods in England ("England's most deprived areas"), and low male life expectancy (“JSNA Blackpool”).

Considering these problems, it is not surprising that many of those who can, leave the resorts to seek a better life elsewhere, which prompted a BBC journalist to state that "young people might disappear from England's seaside towns" (Rhodes). Such a statement is exaggerated, but it points to the fact that those who stay in resorts are usually deprived of better options, and their lives are likely to be blighted by the same problems that are encountered by the older population, probably even more so, given the greater sensitivity of children and young people. The question I wish to pose is whether some recent British films set in coastal resorts confirm the negative perception of seaside towns as unfriendly towards permanent residents who find themselves there not by choice, but by necessity. I am also interested in how three of these films-Jellyfish (2018), directed by James Gardner; Vs. (2018), directed by Ed Lilly; and Eaten by Lions (2018), directed by Jason Wingard-reflect wider discourses about England, concerning class and race. In focusing on these films, I also consider their production values, characters, stories, and location, while relying on research data on coastal resorts, their cinematic representations, Erving Goffman's taxonomy of spaces into "front" and "back regions," and Mikhail Bakhtin's concept of the carnivalesque. 


\section{New coastal resort films}

British films set in coastal resorts belong to a variety of styles and genres. Among them, we find realistic and fantasy films, adventure films, comedies, social dramas and even war films. Until recently, these films adhered to a specific order in representing places and characters, that is, the spaces in these films were strictly divided between Goffman's "front" and "back" regions. The former is the meeting place of hosts and guests, or customers, and service personnel, while the latter is the place to which members of the "home team" retire between performances to relax and to prepare for their next show. Examples of back regions are kitchens, boiler rooms, and executive washrooms, and examples of front regions are reception offices, parlours, and the like. Although architectural arrangements are mobilized to support this division, it is primarily a social one, based on the type of social performance that is staged in a place, and on the social roles involved (Goffman 109-12).

In the bulk of coastal films, tourists and holidaymakers are cast as main characters, being located in "front" regions. They attend variety shows and gliding competitions, walk the promenades, visit fun-fairs, and have their palms read by fortune-tellers. The locals work in "back" regions, preparing spectacles and meals for them, and enter front regions only to cater for their needs. If tourists venture to back regions, this happens by accident, and is presented as an aberration rather than the norm, typically leading to humorous situations, such as in Sing As We Go (1934), directed by Basil Dean. This trespassing does, in fact, maintain the division between front and back regions.

By contrast, in the three films investigated, the principal roles are assigned to locals, or to people who have moved to coastal resorts semi-permanently. Rather than hiding in the back regions, or boldly moving to front regions, they dwell in places that do not fit such descriptions, but belong to everybody, or are on the boundary where front and back become 
blurred. By the same token, these films try to provide visibility to people and problems that normally remain hidden. It can be argued that the "backyards" of the resorts are used here to represent wider problems afflicting British people, such as poverty, the breakup of families, or the lack of prospect for the young.

All three films were made by directors who made their debut in full-length fiction films. Although this does not fully explain why they decided to focus on the "kitchen area," and the "no-man's land" of the resorts, it can be argued that such a choice is advantageous to low budget productions, which is typically the case for first-time directors. The back regions are simple and unadorned, and most convenient as off-the-shelf locations. This setting also links them to the style of socialist realism, which admittedly prevails among left-leaning British directors, such as Tony Richardson, and Ken Loach. By contrast, more established directors, who work with generous budgets, can afford to focus on lavish spectacles taking place in front regions, as is the case in Miss Peregrine's Home for Peculiar Children (2016), and in Yesterday (2019), the former directed by Tim Burton, and the latter by Danny Boyle, which were made concurrently with the three films discussed in this article. Boyle's movie, for example, includes lavish performances of Beatles' songs by the main character and original productions of Ed Sheeran.

\section{The power of spectacle}

The three films focus on underprivileged young people whose difficult positions are the result of their troubled family backgrounds. Fifteen-year-old Sarah in Jellyfish lives with her mother and two younger siblings in Margate, but her mother does not look after any of her children, and is a burden to Sarah, who is left in charge of running the household. The teenager has to look after her brother and sister and make sure the mother does not squander the money she earns working in the arcade, cleaning the machines and performing sexual 
"hand jobs" on older men. Adam in Vs., after being abandoned by his mother, has spent most of his life in foster care, moving from one temporary home to the next, eventually ending up in Southend, where his mother lives and works as a hairdresser. Omar and Pete, teenage stepbrothers in Eaten by Lions, go to Blackpool after the death of their grandmother, who was their carer, as Pete's parents had been eaten by lions. The purpose of their trip is to find Omar's estranged father.

In all these cases living or moving to a resort is presented not as a positive choice, but as a consequence of unfortunate circumstances. The resorts thus act as a trap for them. The feeling of entrapment and disappointment is conveyed most conspicuously by Sarah in Jellyfish, who in her stand-up comedy act, a final project in her drama class, delivered in front of an audience made up of the inhabitants of Margate, lists all the deprivations she has suffered in that town, including having to work instead of going to school and being raped by her employer. She finishes her performance by saying that she has had enough of the place. Subsequently, Sarah runs off the stage, takes her bike, and boards a train, most probably to go to London, but changes her mind and gets off before the train departs. It is impossible to determine whether she decides to stay out of concern for her siblings because she realizes that leaving Margate will not solve her problems, or because she has discovered her vocation as a stand-up comedian.

Adam in $V s$. is presented as an angry young man who feels let down by practically everybody: his mother, who puts him into foster care, and his carers, for whom he is just a task to fulfill, and he expresses his rage by smashing the furniture and other objects in his apartment. He continues his angry behavior in Southend, where he meets Makayala, a young Black woman who is working in an arcade. She takes an interest in Adam and introduces him to the rap battle scene in her town. Consequently, like Sarah, he finds a way to channel his anger into creative endeavor. Also, in common with Sarah, his audience are the inhabitants of 
the resort; tourists in the town are excluded from the show. Moreover, the performers and the audience are constantly changing places; this is the rule of the rap battle. Rather than waiting to be noticed by an audience in the "front region," the characters merge the front and back regions, taking possession of both.

Finally, in Eaten by Lions ${ }^{1}$ Omar and Pete do not assume any straightforward performing identities. Neither do they go to any official performances. However, their trip to Blackpool is presented as a kind of a multi-layered performance, in which the boys are both the audience and the actors. First they are the audience, when they go to a (male) clairvoyant, who- like every fortune teller would - pretends to know the past and the future. It turns out that the man does indeed know something about the boys' circumstances and is able to help them to trace Omar's family. Another example is their trip to the hotel, whose owner meets them in a fancy dressing gown, which turns out to be his usual appearance. Finally, we observe a kind of theater in the house of Omar's Pakistani relatives. First, the relatives look at the boys as if they were some kind of spectacles, being so different from them, and their gaze is reciprocated: the boys look back at the relatives, acknowledging their difference and distance. The positioning of the guests and hosts as the providers and recipients of the spectacle is emphasized by the composition of the scene, the camerawork, and dialogue. Both groups are placed in the center of a frame and are at a significant distance from each other, as is the case with actors and audiences in the theater, and the Pakistani group looks as if they were posing for a family photograph. Initially, we do not see them together; we see either one group, or the other. This separation reflects the arrangement of a traditional theater where the stage and the audience are allocated their distinct spaces. The two groups of people are shown in a long shot, which increases the distance between them. At some point Pete takes a few things from his pocket, as if he were a magician, saying "exhibit 1," "exhibit 2," and asking "can people at the back hear me?," which is a question one expects to hear during a 
performance rather than at a family gathering. The sense that we are observing two alternating performances, one offered by the hosts, one by the guests, is augmented when Omar's father appears on the "scene". He is singing and dancing as he enters his brother's house, as if he was a pop star, in shiny clothes, complete with golden buttons adorning his jacket, a golden necklace, wearing a mohawk hairstyle. Such an appearance is in contrast to that of his relatives, who all wear traditional Pakistani attires. He is met with his audience's enjoyment mixed with exasperation. When the family move to the kitchen, the stage-audience dynamics is maintained, with the guests on one side of the table and the hosts on the other, despite the fact that the space is tighter in the kitchen than in a sitting room. Gradually, however, the physical distance between the performers and the audience is reduced, and the roles are reversed more frequently, especially between one of the daughters of the Pakistani family, Parveen, and Pete. The girl pretends to be mute, because - as she reveals it to Pete-nobody pays attention to her. To get Pete's full attention, she starts to create mini-spectacles for his enjoyment, such as playing with her fan or putting a finger in her mouth, which obviously has erotic connotations, before stealing his grandfather's flashy car and driving Pete to the beach, and then to the town center.

These multiple spectacles signal the alienation of the young characters, who are ignored, misunderstood, and even abused by their families and friends, while serving as a means as well to draw attention to their plight and their desire to take possession of their surroundings. Their goal is achieved during the course of the narratives: the spectacles are successful, the performers and the audience are moved by them, although they often do not explicitly enjoy them. Although a spectacle is, by its very nature, staged and short, it is not a "normal" reality, and thus can be easily ignored and forgotten. This fact was first recognized by Mikhail Bakhtin in his writings about the "carnival," understood as a special place and time, where people can reject censorship and live out their wildest desires. 
As opposed to official feasts, one might say that carnivals celebrate temporary liberation from the prevailing truths and from the established order; they mark the suspension of all hierarchical ranks, privileges, norms, and prohibitions. The carnival season is the true feast of time, the feast of change, and renewal. It is hostile to all that is immortalized, rigidly fixed, or finalized. This temporary suspension, both imagined and real, of hierarchies creates a special type of communication that would be impossible in everyday life. This has led to the creation of special forms of marketplace speech and gesture, free and frank, permitting no distance between those who come in contact with each other, liberating them from the constraints of etiquette, from the rules of expected and accepted social behaviors imposed at other times.

The ultimate purpose of the carnival is to act as a safety valve, ensuring that the normal order prevails, and, ultimately, nothing changes with the festivities over. From this perspective, each film offers us a different scenario. In the case of Jellyfish, the performance is a turning point because it makes Sarah's teacher aware of the deprivations and abuses the girl has suffered. We can assume that she would not return to her previous life even if she stayed in Margate. For Adam, spectacle comes across as a means to alleviate his disappointments and grievances related to his neglect by his mother, and, at the same time, to amplify them. As Peter Bradshaw notes:

All his rage and alienation are alchemised into brilliant rhymes. He knows how to stand his ground when his opponent gets right in his face with the nastiest jeers. But his case workers are worried. Is this a miracle? All his anger magically transformed into something non-violent and creative? Or is Adam developing a dangerous new addiction to confrontation that will keep the violence alive in his heart when it should be dying away? Everything comes to a head when his rap contests appear alongside 
confrontations with his mum, and his head-butting rage becomes ever more painful. (Bradshaw)

Finally, the spectacles in which Pete and Omar participate allow them to gain more independence from each other through their engagement with other people: Omar with Amy, the White employee of the Aquarium, and Pete with the Asian girl Parveen. Both couples are testing new identities, eventually deciding to live together again, but on this occasion such a decision is the result of their choice, rather than a necessity.

\section{Class and race}

Films set in coastal resorts typically include an element of romance, which is often combined with a motif of self-discovery. For example, in Hindle Wakes the main female character, while having an affair with an upper-class man, realizes that she does not need a man to be fulfilled; indeed, she prefers to remain independent. In Sing As We Go, Grace is attracted to her boss, but he falls for an upper-class girl from London. In these early films class difference is a crucial issue affecting the chance of romance that renders it impossible or difficult to happen.

In the three films discussed in this paper, class position is an important issue for the characters, as they are absolutely or relatively poor, but it is not the problem that hinders them in forging close relations with other people. Significantly, however, they build these relationships with people of different skin colors than theirs. In Vs., the White Adam is first looked after by a Black social worker, and then becomes enchanted by the Black and charismatic Makayala, who recognizes his talent as a rapper and helps him to channel his anger into art. In Eaten by Lions, Omar develops a friendship with the White girl working for the Aquarium, and Pete with a Pakistani girl. In Jellyfish, Sarah is first challenged by her 
Black drama teacher to prepare something to perform in front of an audience and is eventually saved by him, as he turns out to be the only person who understands her predicament and is able to help her. In some cases there is an element of an erotic attraction, but this attraction is played down in the narrative or does not lead to erotic fulfillment because of the difference in age, sexual orientation, or due to one of the characters being engaged elsewhere. The focus is on "rescuing" the vulnerable youngster so that he or she does not sink into depression or selfdestructive anger. Moreover, in Jellyfish and Vs. people of color come across as more noble than their White counterparts because they do not take advantage of anyone vulnerable, unlike Sarah's White boss, who rapes her, or a man she meets in a pub, who wants to use her as a prostitute.

In Eaten by Lions, Pete's White aunt and her husband agree to look after him following the death of Pete's grandmother, but the aunt turns out to be unkind and racist, making Omar feel that he is unwelcome in her house. She also makes racist comments when visiting Omar's family in Blackpool. Omar's family, ultimately, prove to be more sympathetic to Pete, understanding and accepting that the step-brothers do not want to be separated.

In idealizing people of color and criticizing White people, especially middle-aged White men, the films promote what is termed as "diversity" and "multiculturalism," ideals promoted by many cultural institutions, including academia and the liberal media, such as The Guardian, which dismiss criticism of ethnic minorities as racist and, at the same time, play up the faults of the White majority. In a wider sense, the focus on race as opposed to class can be regarded as a reflection of the dominance of identity politics in Britain in recent decades, at the expense of class politics (Mazierska 2-3).

It is possible that presenting White women as irresponsible parents, and White men as sexual abusers, while introducing people of color as the saviors of vulnerable White youngsters, helped producers of these films obtain funding and secure positive reviews. 
While lamenting the fate of young people in coastal resorts, the films conspicuously omit the issue of limited economic opportunities for the people living in the resorts, which increasingly leads to the exodus of the young from there. Nor do they mention, for that matter, how meager the government support is to low-income families with children. In Jellyfish, in particular, the blame for having little to eat and for living under the threat of her electricity supplies getting cut off any day, is put squarely on Sarah's reckless mother, who is too lazy to turn up to collect her unemployment benefits. Thus she comes across as a single mother with children sponging off the state, as demonized by Margaret Thatcher during her premiership.

\section{Location}

In his seminal book about working-class life, The Uses of Literacy, Richard Hoggart observes:

Most working-class pleasures tend to be mass-pleasures, over-crowded and sprawling. Everybody wants to have fun at the same time, since most buzzers blow within an hour of each other. Special occasions - a wedding, a trip to the pantomime, a visit to the fair, a charabane outing-assume this, and assume also that a really special splendour and glitter must be displayed. (120-21)

The films with locations in seaside resorts made before the Second World War, such as Sing As We Go, Hindles Wake, and, to some extent, No Lady (1930) follow this rule. They show crowds of people indulging in ephemeral pleasures, such as visiting fairgrounds and eating candy floss. On such occasions most of the joy results from being together, either with friends from one's factory, or meeting new people, for which chances during the working week are limited. 
Free Cinema and New Wave films in the 1950s still showed communal pleasures, but these were increasingly presented critically as examples of the degeneration of working-class culture and discord, such as $O$ Dreamland (1954) by Lindsay Anderson, A Taste of Honey (1961), directed by Tony Richardson, and Saturday Night and Sunday Morning (1960), directed by Karel Reisz. John Hill observes that

The Blackpool amusements sequence in A Taste of Honey, for example, is practically a reprise of Anderson's $O$ Dreamland. There is exactly the same emphasis on degrading spectacle and its culturally repellent mix of prurience, ghoulishness and pseudo-art. . . . Like $O$ Dreamland, the characters themselves are made to look grotesque, stuffing themselves with food, matching their heads to model cavemen's bodies, disfiguring themselves in front of distorting mirrors. And, in a practical steal, there is a cut from the close-up of a woman's face to a model clown in a glass cage, linked by their mutually repulsive laughter. (152-53)

My own judgement of how the resort pleasures are depicted is less critical than Hill's, who in his critical assessment of such scenes might betray his own prejudice against what Hoggart describes as typical working-class taste, marked by affinity to bright colors, ornamentation, and distortion. What is important is that in the New Wave films excursions to funfairs shed light on discord within families. This is most conspicuously presented in A Taste of Honey, where Jo is offended and disgusted by her mother's gravitating towards her lover and leaving her behind. From the 1990s on, more and more films are set in the off-season, in large part to emphasize the desolation of the once thriving resorts and, by the same token, the decline and disappearance of working class culture. From this perspective, Pawel Pawlikowski's Last Resort (2000) constitutes a prime example, with a title which speaks for itself. 
The films discussed in this article borrow certain elements from the earlier films but do not reproduce any of these models. They do not show thriving resorts, full of tourists, but neither do they present the coastal towns as deserted. There are people in places where the characters venture, but not crowds, and typically the people they meet are not tourists. We find, for example, a school and a job center in Jellyfish and a non-descript residential area in Eaten by Lions, which in part reflects the fact that the characters themselves are not tourists, hence they do not go to the places that tourists frequent, and if they do, it happens only "afterhours." An example is Omar and his female friend's evening visit to Blackpool beach, where they are by themselves, playing, and going to the aquarium when it is locked. When the characters go to the "temples of instant gratification," where tourists congregate, they are alienated from their surroundings. For example, Omar and Pete visit a shop with tacky souvenirs, managed by Omar's father, who shows the boys a pen with an Asian woman taking off her clothes.

Another example is Sarah and her family going to Dreamland in Jellyfish. The attraction is not entirely deserted, but has only a few visitors. What is important is that it is not a site of after-work pleasure, but a place where Sarah's mother goes instead of work. Because of this undeserved pleasure, Sarah does not enjoy the trip and it ends badly, as it makes Sarah rush and entrust her mother with paying the bills, which the mother fails to do, buying a van instead to go on holiday. The scene in Dreamland brings to mind one in A Taste of Honey, as in both films it is the mother rather than the teenage daughter who shows an excessive appetite for fun. The rollercoaster in this film with its circular route and predetermined ending points to Sarah's entrapment in Margate.

Unlike the characters in earlier films, the protagonists of these three "teenage" films do not search for crowds but avoid them, choosing places where there are few people, such as beaches and promenades. Beaches constitute an attraction for tourists, but they are not 
purpose-built, and they are free for everybody. From this perspective, they do not belong solely to tourists and they are not divided into front and back regions. For Omar, a trip to the beach constitutes a life-changing experience, as he discovers freedom in rambling through an empty space. On Sarah, the beach does not have such a transformative effect, yet the only time when she appears as a careless child is when she is looking at a beach from the promenade with her younger sister and brother, and they throw some seaweed at a kissing couple before running away.

A promenade, like a beach, is a liminal space not only because it connects (or divides) life and death, nature and culture, but also because it connects the tourists and the natives; everybody can walk the promenade. A promenade is perhaps the most important location in these films, as the characters enter it in a moment of crisis, usually after a dramatic event. Sarah, for example, runs from the house of a man who has tried to have sex with her; Adam finds himself on a promenade after a confrontation with his mother, having accused her of abandoning him. One can expect that they might commit suicide, given that there is the sea on the other side of the promenade, with its association with death. Omar, who scatters his grandmother's ashes into the sea off the promenade and is reprimanded for it by a policeman, is fully aware of this. However, nothing dramatic happens; the walk along the promenade leads the characters to a better place, metaphorically speaking. Adam, for example, meets there a single mother, with whom he has sex. Long takes and long shots used in such scenes underscore the loneliness and isolation of the young characters, as they clearly mark the distance between them and other people who might venture there.

Another characteristic of the location in each film is its fragmentation. We never see the whole city, only sections of it, and it is impossible to determine how different locations are connected with each other. In Eaten by Lions and in Jellyfish, at some points certain locations are frozen, adding to the sense of them being disjointed. Such fragmentation can be 
interpreted as a sign of the characters being unable to take possession of the towns where they dwell; they are neither tourists, nor locals. The in-between status of the resorts, the polarity of thriving and dying, serving the tourists and the natives, is underscored by the difficulty of establishing the season in which a given film is set. The characters typically wear casual clothes, such as hoodies and trousers. It is never hot summer, but it is not autumn or winter either. It feels like the time is not good enough for them to stay, nor is it bad enough to make them leave.

\section{Conclusion}

The three films under scrutiny recognize the difficult situation of young people living in coastal resorts, as demonstrated by their exodus, which makes British resorts the domain of older people, largely on low incomes. At the same time, they try to show ways by which the young who cannot leave might improve their situation, pointing to performance as a privileged means to make the town their own. They also focus on forging inter-racial relations as a means to overcome problems in White families. What is also characteristic about these films is their inconclusiveness. In part, this can be seen as testimony to their status as arthouse, or realistic, films, which shun happy endings typical to Hollywood films, but in part also as a reflection of the situation of their characters and, by extension, of that of thousands of other young people like them who do not want to stay in their hometown resorts, but have nowhere to go. 


\section{Notes}

${ }^{1}$ The title of the film might be a reference to Stanley Holloway's 1932 recording of a comic monologue with musical accompaniment, The Lion and Albert. It begins with "There's a famous seaside place called Blackpool, that's noted for fresh air and fun." It goes on to tell the story of a small child eaten by a lion at Blackpool zoo, a narrative whose ostensible horror is humorously undercut by the phlegmatic, matter-of-fact pragmatism of the cast of workingclass characters.

\section{Works cited}

Bakhtin, Mikhail. "From M. M. Bakhtin, Rabelais and His World." The Bakhtin Reader: Selected Writings of Bakhtin, Medvedev, Voloshinov. Ed. Pam Morris. London: Edward Arnold, 1994. 195-244. Print.

Bradshaw, Peter. "VS. review-the 8 Mile of Southend." The Guardian, 19 Oct. 2018. Web. 20 Feb. 2020.

"England's most deprived areas named as Jaywick and Blackpool.” BBC News, 26 Sept. 2019. Web. 27 Sept. 2019.

Goffman, Erving. The Presentation of Self in Everyday Life. London: Penguin, 1959. Print.

Hill, John. Sex, Class and Realism: British Cinema 1956-1963. London: BFI, 1986. Print.

Hoggart, Richard. The Uses of Literacy: Aspects of Working-class Life, with Special References to Publications and Entertainment. London: Chatto and Windus, 1967. Print.

“JSNA Blackpool. Life Expectancy.” Web. 6 Aug. 2019.

Mazierska, Ewa. "Introduction." Contemporary Cinema and Neoliberal Ideology. Ed. Ewa Mazierska and Lars Kristensen. London: Routledge, 2018. 1-21. Print. 
Rhodes, David. “"England's seaside towns where young people might disappear.” $B B C$ News, 21 July 2019. Web. 5 Aug. 2019. 